\title{
PENGARUH REPETITIVE TRANSCRANIAL MAGNETIC STIMULATION (r-TMS) TERHADAP INTENSITAS NYERI PENDERITA CENTRAL POST-STROKE PAIN (CPSP)
}

\author{
EFFECTS OF REPETITIVE TRANSCRANIAL MAGNETIC STIMULATION \\ (r-TMS) TOWARDS PAIN INTENSITY IN PATIENTS WITH CENTRAL \\ POST-STROKE PAIN (CPSP)
}

Dody Perdana Goenadhi, * Jumraini Tammasse, * David Gunawan*

\section{ABSTRACT}

Introduction: About 2,7\% patients have experienced central post-stroke pain (CPSP) after stroke attack. Repetitive transcranial magnetic stimulation ( $r$-TMS) is a nonpharmacological method to overcome CPSP.

Aims: To determine the effectiveness of $r$-TMS to reduce pain intensity in patients with CPSP.

Methods: Randomized-controlled trial in Wahidin Sudirohusodo hospital and Inggit clinic from December 2017 until May 2018. Subjects were divided to 2 groups; control, who received standard therapy for CPSP, and treatment, who received standard therapy for CPSP and $r$-TMS. Repetitive transcranial magnetic stimulation was done using 2000 pulse and $10 \mathrm{~Hz}$ frequency. Pain intensity was measured with Numerical Pain Rating Scale (NPRS) at baseline, after r-TMS until day 10. Data analysis was done by Mann-Whitney test.

Results: As much as 30 subjects were divided into 2 groups (15 control and 15 treatment). The difference in NPRS score after 10 days of treatment was statistically higher in the treatment group compared to the control $(6,67 \mathrm{vs} 4,67$, $p=0,002$ ).

Discussion: There was a significant reduction in pain intensity in the group given r-TMS for 10 cycles.

Keywords: Central pain, NPRS, r-TMS, stroke

\section{ABSTRAK}

Pendahuluan: Sebanyak 2,7\% pasien mengalami central post-stroke pain (CPSP) setelah serangan. Efektivitas repetitive transcranial magnetic stimulation (r-TMS) merupakan salah satu metoda nonfarmakologis untuk mengatasi CPSP.

Tujun: Mengetahui efektivitas repetitive transcranial magnetic stimulation (r-TMS) terhadap penurunan intensitas nyeri pada penderita CPSP.

Metode: Uji klinis terandomisasi di RSUP Dr. Wahidin Sudirohusodo dan Klinik Inggit dari Desember 2017 hingga Mei 2018. Subjek dibagi menjadi 2 kelompok, kelompok kontrol yang mendapat terapi standar dan kelompok perlakuan yang ditambahkan r-TMS. Repetitive transcranial magnetic stimulation dilakukan sebanyak 2000 pulse dengan frekuensi 10Hz. Nyeri diukur dengan Numerical Pain Rating Scale (NPRS) sebelum dan pascaterapi hingga hari ke-10. Analisis data dilakukan dengan uji Mann-Whitney.

Hasil: Didapatkan 30 subjek yang dibagi menjadi 2 kelompok (15 kontrol dan 15 perlakuan). Selisih skor NPRS setelah sepuluh hari terapi lebih besar secara signifikan pada kelompok perlakuan dibandingkan dengan kontrol (6,67 vs $4,67, \mathrm{p}=0,002)$.

Diskusi: Terdapat penurunan intensitas nyeri yang signifikan pada kelompok yang diberikan r-TMS selama 10 siklus.

Kata kunci: Central pain, NPRS, stroke, r-TMS

*Departemen Neurologi FK Universitas Hasanuddin/RSUP Dr. Wahidin Sudirohusodo, Makassar. Korespondensi: dodygoenadhi@ gmail.com.

\section{PENDAHULUAN}

Stroke merupakan penyebab utama kecacatan jangka panjang di usia dewasa. ${ }^{1}$ Di RSUP Dr. Wahidin Sudirohusodo, stroke menduduki urutan pertama dari seluruh jumlah pasien yang dirawat di bangsal neurologi pada periode 2012-2013. ${ }^{2}$ Salah satu komplikasi pascastroke adalah central poststroke pain (CPSP) yang sering dilupakan dalam terapi, padahal sangat memengaruhi kualitas hidup penderitanya. ${ }^{3}$ Studi prospektif terbesar meliputi 15.754 partisipan dari 35 negara menemukan bahwa 2,7\% pasien stroke akan mengalami CPSP 1 tahun setelah serangan stroke..$^{3-4}$

Central post-stroke pain merupakan bagian dari sindrom nyeri sentral, suatu kondisi neurologis yang disebabkan oleh kerusakan atau disfungsi dari 
sistem saraf pusat (SSP), yang dapat disebabkan oleh stroke, multipel sklerosis, tumor, epilepsi, otak atau trauma medula spinalis. Rasa sakit yang terkait dengan sindrom ini berbeda antara individu. Sindrom nyeri sentral dapat memengaruhi sebagian besar tubuh atau mungkin lebih terbatas ke daerah-daerah tertentu. ${ }^{1}$

Nyeri biasanya konstan, mungkin sedang sampai berat, sering diperburuk oleh sentuhan, gerakan, emosi, dan perubahan suhu, terutama dingin. Seseorang dapat mengalami satu atau lebih jenis sensasi nyeri, yang paling menonjol rasa terbakar, kesemutan, atau rasa sakit yang tajam. Sindrom ini sering dimulai tak lama setelah cedera, tetapi mungkin tertunda bulan atau bahkan bertahun-tahun, seperti halnya nyeri pascastroke. ${ }^{1}$

Central post-stroke pain terkait dengan lesi stroke pada traktus spinotalamikus, terlepas dari jenis strokenya. Awalnya diidentifikasi talamus sebagai sumber CPSP, namun penelitian yang lebih baru menunjukkan bahwa jenis nyeri memiliki patofisiologi yang jauh lebih kompleks. Pada dasarnya semua pasien dengan CPSP memiliki gangguan rasa suhu dan nyeri yang menunjukkan keterlibatan jalur spinotalamikus. ${ }^{5}$

Selain gangguan sensorik, stroke juga dapat memengaruhi fungsi motorik, akibat kedekatan anatomi dari traktus motor ke sensorik. ${ }^{5}$ Oleh karena itu, repetitive transcranial magnetic stimulation (r-TMS), deep brain stimulation (DBS), dan motor cortex stimulation (MCS) dilaporkan dapat menjadi tata laksana nonfarmakologi untuk CPSP. Namun dalam beberapa penelitian, rekomendasi untuk MCS dan DBS tidak meyakinkan dalam pengobatan CPSP. ${ }^{4,6}$

Penelitian sebelumnya menggunakan r-TMS $5 \mathrm{~Hz}$ pada korteks motorik primer mendapatkan perbedaan jelas antara perbaikan skala nyeri memakai r-TMS $5 \mathrm{~Hz} 500$ pulse per sesi dengan sham r-TMS. ${ }^{7}$ Hal ini menunjukkan efek positif r-TMS pada penurunan intensitas nyeri sentral pascastroke yang masih dibutuhkan pembuktian lanjut, sehingga dilakukanlah penelitian ini.

\section{TUJUAN}

Mengetahui pengaruh r-TMS terhadap intensitas nyeri pada pasien dengan CPSP.

\section{METODE}

Penelitian ini merupakan uji klinis terandomisasi yang dilakukan di RSUP Dr. Wahidin Sudirohusodo dan Klinik Inggit, Makassar, pada bulan Desember 2017 hingga Mei 2018. Kriteria inklusi meliputi pasien stroke iskemik serangan pertama yang menderita CPSP dalam waktu 3 tahun setelah onset, berusia 30-70 tahun, dan menandatangani surat pernyataan persetujuan.

Central post-stroke pain ditegakkan berdasarkan gejala klinis dan pemeriksaan fisik berdasarkan kriteria diagnostik berupa kriteria wajib dan kriteria suportif. Kriteria wajib meliputi nyeri pada area tubuh yang berkorespondensi dengan lesi pada susunan saraf pusat; riwayat stroke dan onset nyeri saat atau setelah onset stroke; konfirmasi pencitraan dari lesi susunan saraf pusat atau tanda sensori positif maupun negatif yang terbatas pada area yang berkorespondensi dengan lesi; dan sebab lain dari nyeri telah dieksklusi. Kriteria suportif meliputi nyeri yang tidak berhubungan langsung dengan gerakan, inflamasi, atau kerusakan jaringan lokal lainnya; deskripsi nyeri (terbakar, tersetrum, tertekan, tertusuk jarum); dan alodinia atau disestesia terhadap sentuhan atau suhu dingin. ${ }^{8}$

Pasien dieksklusi dari penelitian jika terdapat gangguan kesadaran, gangguan pendengaran, neuropati perifer, gangguan fungsi ginjal, hati, dan jantung yang dapat mengganggu perhatian atau konsentrasi; serta gangguan mental/jiwa, depresi, dan afasia. Kriteria drop out meliputi pasien yang tidak mengikuti sesi r-TMS satu kali atau lebih saat penelitian berlangsung, meninggal dunia, atau mengundurkan diri karena alasan tertentu.

Subjek dirandomisasi untuk masuk ke dalam salah satu kelompok (perlakuan atau kontrol). Dilakukan anamnesis dan pemeriksaan fisik untuk mendapatkan letak sisi paresis dengan hasil CT scan kepala, serta penilaian Numerical Pain Rating Scale (NPRS) awal (hari 0). Selisih skor nyeri dianggap bermakna bila selisih skor NPRS $\geq 3 ., 4$

Terapi standar berupa gabapentin 100mg setiap 12 jam peroral kepada kedua kelompok. Adapun r-TMS hanya diberikan kepada kelompok perlakuan sebanyak satu kali setiap hari selama 10 hari. Hasil terapi ditentukan berdasarkan skor NPRS kedua 
kelompok yang diukur setiap hari sampai hari ke-10.

Alat yang digunakan adalah TMS merk Neurosoft MS-D dan koil berbentuk angka 8 (eight-shaped). Saat terapi, subjek duduk dengan kedua lengan diletakkan di atas paha, posisi lengan menghadap ke atas. Koil diletakkan dalam posisi tangensial pada area presentralis kontralateral dari sisi yang nyeri. Resting motor threshold (RMT) ditentukan dan kekuatan intervensi ditetapkan 80\% dari RMT; diberikan impuls $10 \mathrm{~Hz}$ sebanyak 2000 pulse pada korteks motorik primer, diselingi istirahat selama 5 menit, dilanjutkan impuls $5 \mathrm{~Hz}$ sebanyak 1200 pulse pada dorsolateral prefrontal cortex (DLPFC).

Penelitian ini sudah mendapat persetujuan dari Komite Etik Penelitian Kesehatan FK Universitas Hasanuddin dengan nomor rekomendasi persetujuan etik nomor 284/H4.8.4.5.31/PP36-KOMETIK/2018. Analisis data menggunakan program SPSS versi 21. Uji Mann-Whitney digunakan untuk menilai perbedaan skor NPRS antara kedua kelompok.

\section{HASIL}

Sebanyak 30 subjek penelitian ini dibagi menjadi kelompok kontrol dan perlakuan, masingmasing 15 orang. Didapatkan sebagian besar subjek adalah laki-laki $(60 \%)$ dan berusia $>45$ tahun $(90 \%)$. Tidak terdapat perbedaan data demografik yang bermakna antara kedua kelompok (Tabel 1). yang sejalan dengan rerata selisih penurunan skor NPRS pascaterapi hari kelima dan kesepuluh pada kelompok perlakuan lebih besar secara signifikan (masing-masing $\mathrm{p}<0,001$ dan $\mathrm{p}=0,002$ ) dibandingkan kontrol (Tabel 3 dan Gambar 2).

\section{DISKUSI}

Penelitian ini menghimpun 30 subjek dengan CPSP yang masing-masing terdiri dari 15 subjek pada kelompok kontrol yang hanya diberikan terapi standar dan kelompok perlakuan yang ditambah dengan terapi r-TMS sebanyak 10 siklus. Mayoritas subjek adalah laki-laki dengan usia lebih dari 45 tahun.

Rerata nilai NPRS kelompok kontrol pascaterapi standar selama 5 hari adalah 6,53 , sedangkan nilai rata-ratanya pada hari ke 10 adalah 3,87 . Tampak juga rerata nilai NPRS kelompok perlakuan selama 5 hari adalah 4,40 yang menurun menjadi 2,13 pada hari ke-10. Baik kelompok kontrol maupun perlakuan didapatkan pengurangan rata-rata skor NPRS yang lebih besar pada hari ke sepuluh, berdasarkan terapi standar yang diberikan. Namun rerata penurunan skor NPRS pada kelompok perlakuan lebih besar dibandingkan kelompok kontrol $(\mathrm{p}<0,05)$ yang diduga disebabkan oleh terapi r-TMS. Rerata selisih penurunan skor NPRS pada kelompok kontrol adalah 2 pada hari ke-5 dan 4,67 pada hari ke-10, sedangkan rerata selisih penurunan skor NPRS pada kelompok

Tabel 1. Karakteristik Demografi Kedua Kelompok $(n=30)$

\begin{tabular}{lccc}
\hline \multicolumn{1}{c}{ Karakteristik } & $\begin{array}{c}\text { Kelompok Kontrol } \\
(\mathbf{n = 1 5})\end{array}$ & $\begin{array}{c}\text { Kelompok Perlakuan } \\
(\mathbf{n = 1 5 )}\end{array}$ & $\mathbf{p}$ \\
\hline Usia & & & \\
- $\leq 45$ tahun & $2(13 \%)$ & $1(7 \%)$ & 0,482 \\
- $>45$ tahun & $13(87 \%)$ & $14(93 \%)$ & 0,394 \\
Jenis Kelamin & & & \\
- Laki-laki & $8(53 \%)$ & $8(53 \%)$ & 0,615 \\
- Perempuan & $7(47 \%)$ & $7(47 \%)$ & 0,504 \\
\hline
\end{tabular}

Kedua kelompok memiliki skor NPRS sebelum terapi yang sama, yaitu 7-10 (Tabel 2). Selanjutnya terlihat perbandingan nilai NPRS yang bermakna antara kedua kelompok sejak hari pertama (masingmasing $\mathrm{p}<0,001$ dan $\mathrm{p}=0,001$ ), yaitu kelompok perlakuan memiliki nilai NPRS yang lebih rendah dibandingkan kontrol (Tabel 2 dan Gambar 1). Hal perlakuan adalah 4,4 pada hari ke-5 dan 6,67 pada hari ke-10.

Penelitian sebelumnya mendapatkan perbedaan antara perbaikan skala nyeri dengan r-TMS $5 \mathrm{~Hz} 500$ pulse per sesi dengan sham r-TMS. ${ }^{4}$ Pada penelitian ini, pemberian impuls dengan frekuensi $10 \mathrm{~Hz}$ dilakukan pada korteks motorik primer $10 \mathrm{~Hz} 2000$ 
Tabel 2. Perbedaan Rerata Skor NPRS Kelompok Kontrol dan Perlakuan Pre- dan Pascaterapi $(n=30)$

\begin{tabular}{lccc}
\hline \multicolumn{1}{c}{ Skor NPRS } & $\begin{array}{c}\text { Kelompok Kontrol } \\
(\mathbf{n}=\mathbf{1 5})\end{array}$ & $\begin{array}{c}\text { Kelompok Perlakuan } \\
(\mathbf{n}=\mathbf{1 5})\end{array}$ & $\mathbf{p}$ \\
\hline Hari 0 & $8,53 \pm 0,915$ & $8,80 \pm 0,914$ & 0,486 \\
Hari 1 & $7,93 \pm 1,534$ & $6,40 \pm 1,056$ & 0,000 \\
Hari 2 & $7,87 \pm 1,125$ & $5,33 \pm 0,900$ & 0,000 \\
Hari 3 & $7,67 \pm 1,234$ & $5,20 \pm 1,014$ & 0,000 \\
Hari 4 & $7,00 \pm 0,926$ & $4,87 \pm 0,834$ & 0,000 \\
Hari 5 & $6,53 \pm 0,990$ & $4,40 \pm 0,737$ & 0,006 \\
Hari 6 & $5,60 \pm 1,404$ & $4,20 \pm 1,014$ & 0,008 \\
Hari 7 & $5,27 \pm 1,280$ & $3,87 \pm 1,246$ & 0,000 \\
Hari 8 & $5,27 \pm 1,280$ & $3,20 \pm 1,320$ & 0,000 \\
Hari 9 & $4,13 \pm 1,187$ & $2,73 \pm 1,223$ & 0,004 \\
Hari 10 & $3,87 \pm 1,125$ & $2,13 \pm 1,407$ & 0,001 \\
\hline
\end{tabular}

Uji Mann-Whitney; Data primer 2018; NPRS: Numerical Pain Rating Scale.

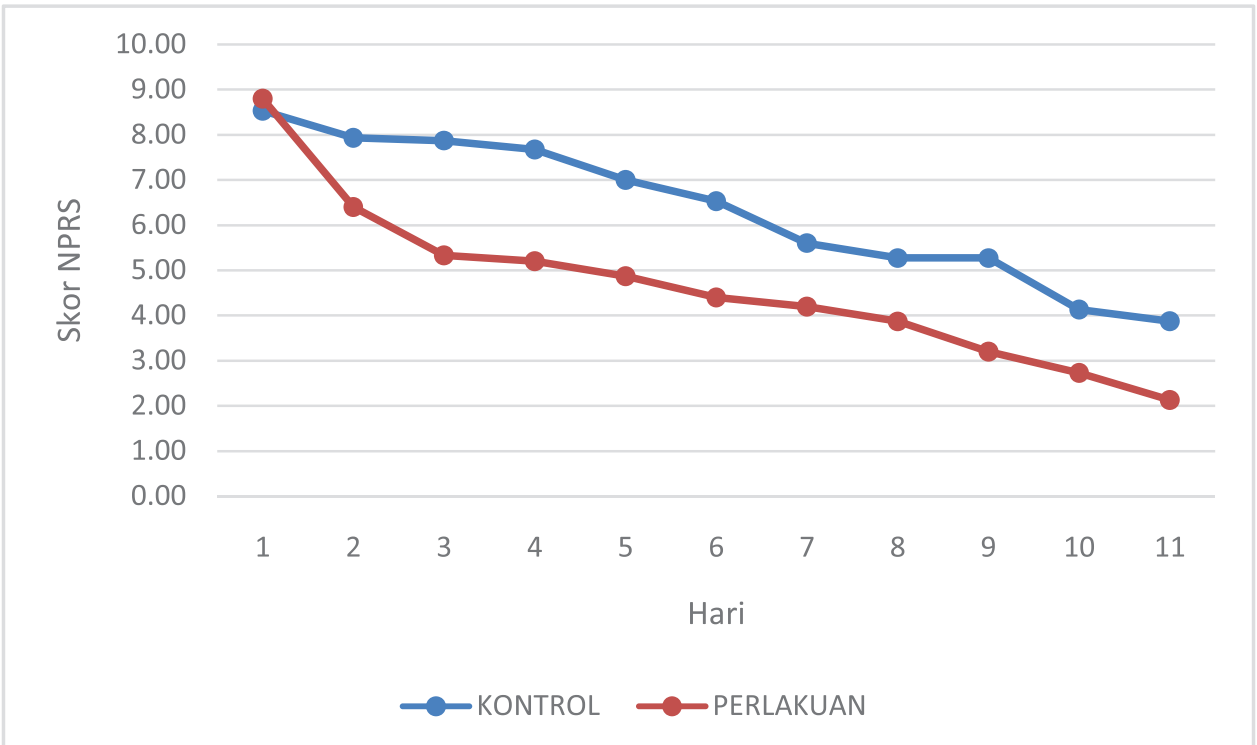

\begin{tabular}{|c|c|c|c|c|c|c|c|c|c|c|c|}
\hline \multirow{2}{*}{ Kelompok } & \multicolumn{11}{|c|}{ Hari } \\
\hline & 1 & 2 & 3 & 4 & 5 & 6 & 7 & 8 & 9 & 10 & 11 \\
\hline Kontrol & 8,53 & 7,93 & 7,87 & 7,67 & 7,00 & 6,53 & 5,60 & 5,27 & 5,27 & 4,13 & 3,87 \\
\hline Perlakuan & 8,80 & 6,40 & 5,33 & 5,20 & 4,87 & 4,40 & 4,20 & 3,87 & 3,20 & 2,73 & 2,13 \\
\hline
\end{tabular}

Gambar 1. Skor NPRS Kedua Kelompok dari Hari 0-10

pulse, diselingi istirahat selama 5 menit, dilanjutkan rangsangan kedua pada DLPFC sebesar $5 \mathrm{~Hz}$ dan sebanyak 1200 pulse. Frekuensi yang digunakan pada penelitian ini adalah frekuensi tinggi $(\geq 5 \mathrm{~Hz})$, yang akan menyebabkan peningkatkan eksitabilitas neuron. Mekanisme yang diduga berperan dalam penelitian ini adalah peningkatan eksitabilitas neuron GABAergik, yang akan meningkatkan jumlah neurotransmiter GABA. ${ }^{7}$
Hasil penelitian ini sesuai dengan penelitian sebelumnya yang menemukan perbedaan bermakna pada selisih skor NPRS antara kelompok kontrol dan perlakuan., ${ }^{4-6}$

Pada pasien dengan CPSP, pemberian terapi standar dan r-TMS mengurangi intensitas nyeri secara signifikan dibandingkan terapi standar saja. Keterbatasan penelitian ini adalah tidak dilakukan- 
Tabel 3. Selisih Skor NPRS pada Kelompok Kontrol dan Kelompok Perlakuan (n=30)

\begin{tabular}{lccc}
\hline Skor NPRS & $\begin{array}{c}\text { Kelompok Kontrol } \\
(\mathbf{n}=\mathbf{1 5})\end{array}$ & $\begin{array}{c}\text { Kelompok Perlakuan } \\
(\mathbf{n = 1 5 )}\end{array}$ & $\mathbf{p}$ \\
\hline Hari 1 & $0,60 \pm 1,352$ & $2,40 \pm 1,121$ & 0,001 \\
Hari 2 & $0,67 \pm 1,047$ & $3,47 \pm 1,125$ & 0,000 \\
Hari 3 & $0,87 \pm 1,187$ & $3,60 \pm 1,121$ & 0,000 \\
Hari 4 & $1,53 \pm 1,060$ & $3,93 \pm 1,033$ & 0,000 \\
Hari 5 & $2,00 \pm 0,926$ & $4,40 \pm 1,121$ & 0,000 \\
Hari 6 & $2,93 \pm 1,534$ & $4,60 \pm 1,121$ & 0,001 \\
Hari 7 & $3,27 \pm 1,387$ & $4,93 \pm 1,223$ & 0,002 \\
Hari 8 & $3,27 \pm 1,387$ & $5,60 \pm 1,352$ & 0,000 \\
Hari 9 & $4,40 \pm 1,549$ & $6,07 \pm 1,335$ & 0,003 \\
Hari 10 & $4,67 \pm 1,447$ & $6,67 \pm 1,589$ & 0,002 \\
\hline
\end{tabular}

Uji Mann-Whitney; Data primer 2018; NPRS: Numerical Pain Rating Scale; Min-Max: minimum-maksimum.

\begin{tabular}{lcccccccccc}
\hline \multirow{2}{*}{ Kelompok } & \multicolumn{10}{c}{ Hari } \\
\cline { 2 - 12 } & $\mathbf{1}$ & $\mathbf{2}$ & $\mathbf{3}$ & $\mathbf{4}$ & $\mathbf{5}$ & $\mathbf{6}$ & $\mathbf{7}$ & $\mathbf{8}$ & $\mathbf{9}$ & $\mathbf{1 0}$ \\
Kontrol & 0,60 & 0,67 & 0,87 & 1,53 & 2,00 & 2,93 & 3,27 & 3,27 & 4,40 & 4,67 \\
Perlakuan & 2,40 & 3,47 & 3,60 & 3,93 & 4,40 & 4,60 & 4,93 & 5,60 & 6,07 & 6,67 \\
\hline
\end{tabular}

Gambar 2. Selisih Skor NPRS Kedua Kelompok dari Hari 0-10

nya follow up dalam jangka waktu yang lebih lama untuk evaluasi efek jangka panjang. Jumlah subjek penelitian ini belum memadai karena studi ini merupakan preliminary study. Efek plasebo belum bisa dihilangkan karena penelitian ini hanya berlangsung selama 10 hari dan langsung dilakukan penilaian segera setelah perlakuan.

\section{KESIMPULAN}

Penelitian ini menunjukkan bahwa pemberian terapi standar ditambah dengan terapi tambahanberupa r-TMS sebanyak 10 siklus selama 10 hari pada penderita CPSP secara bermakna mengurangi intensitas nyeri dibandingkan kelompok yang hanya mendapatkan terapi berupa terapi oral saja.

\section{DAFTAR PUSTAKA}

1. Go AS, Mozaffarian D, Roger VL, Benjamin EJ, Berry JD, Borden WB, dkk. American Heart Association 2020 impact goal. Heart disease and stroke statistics - 2013 update: a report from the American Heart Association. Circulation. 2013;127(1):21-4. 
2. Kementerian Kesehatan Republik Indonesia. Riset kesehatan dasar 2013. Badan Penelitian dan Pengembangan Kementrian Kesehatan: Jakarta; 2013.

3. Raffaeli W, Minella CE, Magnani F, Sarti D. Population-based study of central post-stroke pain in Rimini district, Italy. J Pain Res. 2013;17(6):705-11.

4. Hosomi K, Seymour B, Saitoh Y. Modulating the pain network-neurostimulation for central poststroke pain. Nat Rev Neurol. 2015:11(5);1-10.

5. Jauch EC, Saver JL, Adams HP, Bruno A, Connors JJ, Demaerschalk BM, dkk. Guidelines for the early management of patients with acute ischemic stroke. Stroke. 2013:44(3):870-947.

6. Lefaucheur JP, Andre-Obadia N, Antal A, Ayache $\mathrm{SS}$, Baeken $\mathrm{C}$, Benninger DH, dkk. Evidence- based guidelines on the therapeutic use of repetitive transcranial magnetic stimulation (rTMS). Clin Neurophysiol. 2014;125(11):2150-206.

7. Hawker GA, Mian S, Kendzerska T, French M. Measures of adult pain: visual analog scale for pain (VAS pain), numeric rating scale for pain (NRS pain), McGill pain questionnaire (MPQ), short-form McGill pain questionnaire (SF-MPQ), chronic pain grade scale (CPGS), short form-36 bodily pain scale (SF). Arthritis Care Res. 2011;63(11):240-52.

8. Hesami O, Gharagozli K, Beladimoghadam N, Assarzadegan F, Mansouri B, Sistanizad M. The efficacy of gabapentin in patients with central poststroke pain. Iran J Pharm Res. 2015;14(1):95-101. 